Provided for non-commercial research and education use. Not for reproduction, distribution or commercial use.

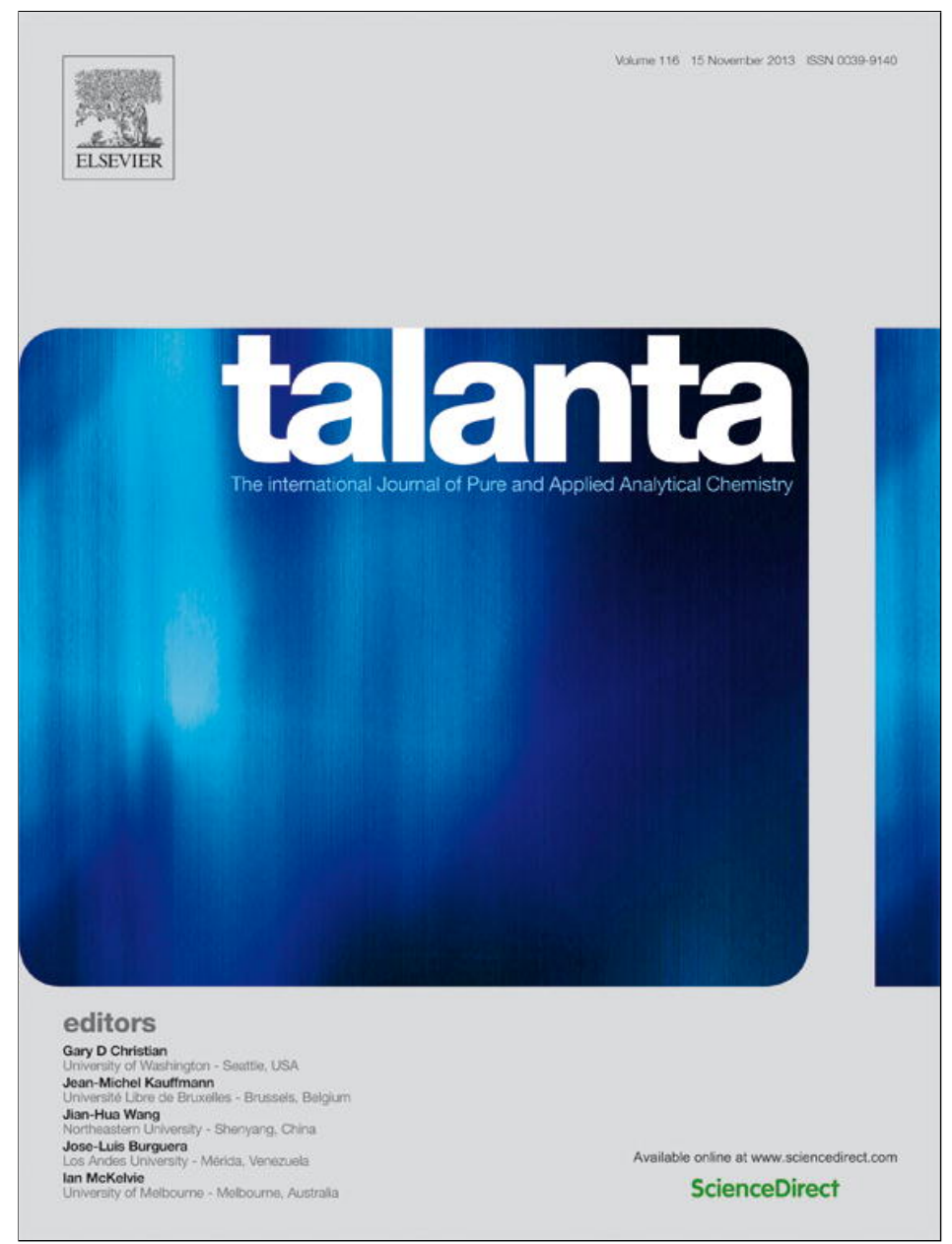

This article appeared in a journal published by Elsevier. The attached copy is furnished to the author for internal non-commercial research and education use, including for instruction at the authors institution and sharing with colleagues.

Other uses, including reproduction and distribution, or selling or licensing copies, or posting to personal, institutional or third party websites are prohibited.

In most cases authors are permitted to post their version of the article (e.g. in Word or Tex form) to their personal website or institutional repository. Authors requiring further information regarding Elsevier's archiving and manuscript policies are encouraged to visit:

http://www.elsevier.com/authorsrights 


\title{
Simultaneous determinations of zirconium, hafnium, yttrium and lanthanides in seawater according to a co-precipitation technique onto iron-hydroxide
}

\author{
Maria Raso $^{\text {a }}$, Paolo Censi ${ }^{\text {a,c }}$, Filippo Saiano ${ }^{\text {b,* }}$ \\ ${ }^{a}$ D.I.S.T.E.M. Department, Università di Palermo, via Archirafi, 36, 90123 Palermo, Italy \\ ${ }^{\mathrm{b}}$ S.A.F. Department, Università di Palermo, viale delle Scienze, ed. 4, 90128 Palermo, Italy \\ ' I.A.M.C. Italian National Research Council, U.O.S. Capo Granitola via del Mare, 3, 91021 Torretta Granitola, Campobello di Mazara (TP), Italy
}

\section{A R T I C L E I N F O}

\section{Article history:}

Received 8 April 2013

Received in revised form

13 August 2013

Accepted 14 August 2013

Available online 23 August 2013

Dedicated to the memory of

Prof. Vincenzo Romano

Keywords:

Validation

Lanthanides

Certified reference material

Co-precipitation

Seawater

Method quantification limit

\begin{abstract}
A B S T R A C T
Very low concentrations ( $\mathrm{pg} \mathrm{mL} \mathrm{mL}^{-1}$ or sub-pg $\mathrm{mL}^{-1}$ level) along with the high salinity are the main problems in determining trace metal contents in seawater. This problem is mainly considered for investigations of naturally occurring YLOID (Y and Lanthanides) and $\mathrm{Zr}$ and $\mathrm{Hf}$ in order to provide precise and accurate results. The inductively coupled plasma mass spectrometry (ICP-MS), both in high and low resolution, offers many advantages including simultaneous analyses of all elements and their quantitative determination with detection limits of the order of $\mathrm{pg} \mathrm{mL}^{-1}$. However in the analysis of YLOID in seawater, a better determination needs an efficient combination of ICP-MS measurement with a preconcentration technique. To perform an ultra-trace analysis in seawater, we have validated an analytical procedure involving an improved modified co-precipitation on iron hydroxides to ensure the simultaneous quantitative recovery of YLOID, $\mathrm{Zr}$ and $\mathrm{Hf}$ contents with measurement by a quadrupole ICP-MS.

The validity of the method was assessed through a series of co-precipitation experiments and estimation of several quality control parameters for method validation, namely working range and its linearity, detection limit, quantification limit, precision and spike recoveries, and the methodological blank choice, are introduced, evaluated and discussed. Analysis of NASS-6, is the first report on the latest seawater reference material for YLOID, hafnium and zirconium.
\end{abstract}

(c) 2013 Elsevier B.V. All rights reserved.

\section{Introduction}

In recent years, increasing attention has been paid to the behaviour and distribution of Y, La and Lanthanides in marine systems because of their unique chemical properties. Their geochemical similarities make them a useful proxy to trace geochemical processes along the water column, ocean circulation and to understand solid-liquid interface processes, as well as to study external sources, physical mixing and scavenging removal processes [1-4].

Further useful elements may be obtained combining information from the behaviour of YLOID and high field strength elements, like $\mathrm{Zr}$ and Hf. The interest in these last two elements is due to their high reactivity and short residence time in the ocean making them potential tracers of water masses or in establishing a firm proxy in paleoceanography [5]. Unfortunately, their distributions, dominated by hydroxide species, $\mathrm{Zr}(\mathrm{OH})_{5}{ }^{-}$and $\mathrm{Hf}(\mathrm{OH})_{5}{ }^{-}$and the

\footnotetext{
* Corresponding author. Tel.: +390912 3897083.

E-mail addresses: rasomaria mr@libero.it (M. Raso)

paolo.censi@unipa.it (P. Censi), filippo.saiano@unipa.it (F. Saiano).
}

difficulty in their analysis with conventional methods, have limited their study in the hydrological cycle.

Understanding geochemical processes in marine systems is only possible if the identification and quantification of these elements in seawater is obtained using reliable and comparable chemical measurements. For this reason the ability of an analytical protocol to obtain reproducible values is paramount. Determination of trace elements in seawater is a challenge mainly for two reasons: first of all because the concentration of these elements ranges from $\mathrm{pg} \mathrm{mL}^{-1}$ to $\mathrm{fg} \mathrm{mL}^{-1}$ and, secondly, because the high salt matrix gives rise to analytical interferences and severe instrumental conditions, i.e. in QICP-MS (Quadrupole Inductively Coupled Plasma-Mass Spectrometry) polyatomic ions mass spectral overlapping, instrumental drift, signal suppression and clogging of the sample introduction system of the instrument. Any of these analytical issues can be solved; for example with the more expensive high-resolution ICP-MS or through suitable systems which, by removing the matrix, allow analytical determinations above the instrumental quantification limits.

To pre-concentrate YLOID or $\mathrm{Zr}$ and $\mathrm{Hf}$ in water samples several methods were developed, including co-precipitation [6], solvent extraction [7] and solid phase extraction [8,9]. Unfortunately, only 
a few studies were carried out with suitable control procedures involving the overall experimental measurements. Often, the assessment of data quality was obtained only by calculating the percentage amounts of YLOID or $\mathrm{Zr}$ and $\mathrm{Hf}$ recovered from solutions in which the elemental concentration of the spikes added were higher with respect to their natural contents in seawater, or with the procedural blank composition not being clearly or exactly defined and not really simulating the seawater matrix [10-14]. Therefore, it is very problematic to compare the results obtained from different studies lacking the traceability of results of the complete analytical procedure that should be established using an appropriate Certified Reference Material (CRM). At present, seawater CRMs are not certified for YLOID, $\mathrm{Zr}$ and $\mathrm{Hf}$, nor is the concentration of these elements given as information values. Therefore, the analytical results cannot be assessed, compared, or interpreted if they are not accompanied by a series of indicators that provide information on the performances of the used method. In recent years "...The processes used to demonstrate the fitness for purpose of analytical methods, thus the ability of a method to produce reliable results, and hence the adequacy for the intended application, defined as validation of the analytical method, is integrated in the quality criteria adopted by every laboratory..." and with the name Quality Assurance are collected and described as "...All the actions undertaken for planning the proper execution of an analytical task" $[15,16]$. General requirements for the performance characteristic for a quantitative method are calibration, involving the goodness of the fit of the calibration function, sensitivity, detection and quantification limits, accuracy study involving trueness, precision, as repeatability or reproducibility, specificity and selectivity. Furthermore, the implementation of the quality criteria allows one to monitor and demonstrate the performance characteristics of methods, to have control over the analytical errors, to avoid erroneous results and to identify the source of errors more satisfactorily.

In order to contribute to the recent efforts to generate validated methods, the aim of this work was to control an analytical methodology for a $\mathrm{Fe}(\mathrm{OH})_{3}$ pre-concentration technique modified to ensure the simultaneous quantitative recovery of YLOID, $\mathrm{Zr}$ and $\mathrm{Hf}$ contents in a complex matrix like seawater with a quadrupole ICP-MS, chosen as the analytical technique. The main parameters evaluated as quality criteria in the validation were: the working range and its linearity, the detection and quantification limits, recoveries, and precision as repeatability and accuracy.

\section{Experimental}

\subsection{Materials and equipment}

All chemicals were of ultrapure grade. Ultrapure water (resistivity of $18.2 \mathrm{M}^{\prime} \Omega \mathrm{cm}$ ) was obtained using an EASY pure II purification system (Thermo, Italy). Nitric acid 65\% (w/w), ammonia 25\% (w/w) and hydrochloric acid 30\% (w/w) were purchased from VWR International. Working standard solutions for each element (Zr, Y, La, Ce, Pr, $\mathrm{Nd}, \mathrm{Sm}, \mathrm{Eu}, \mathrm{Gd}, \mathrm{Tb}, \mathrm{Dy}, \mathrm{Ho}, \mathrm{Er}, \mathrm{Tm}, \mathrm{Yb}, \mathrm{Lu}$ and $\mathrm{Hf}$ ) were prepared on a daily basis by stepwise dilution of the multi-element stock standard solution DBH, Merck or CPI International $\left(1000 \pm 5 \mu \mathrm{g} \mathrm{mL}^{-1}\right)$ in a $1 \mathrm{mmol} \mathrm{mL}^{-1} \mathrm{HCl}$ medium. All lab-wares were polyethylene, polypropylene or Teflon and the calibration of all volumetric equipment was verified. A calibrated E42-B balance (Gibertini, Italy) was used to weigh all samples and standards. All $\mathrm{pH}$ measurements were carried out with HI 991300 pH meter (Hanna Instruments, Italy). The seawater samples were filtered through a $0.45 \mu \mathrm{m}$ filter and acidified to $\mathrm{pH}<2$ with nitric acid before use.

\subsection{Instrumentation and operational parameters}

An ICP-MS instrument (Agilent Technologies 7500ce Series Spectrometer) equipped with a collision cell was used for the analyses of all of the investigated trace elements. All parameters were optimised for the studied elements.

Because both samples and calibration standards were prepared in $\mathrm{HCl} 1 \mathrm{M}$, we have carefully tuned the mass spectrometer with a solution containing $1 \mathrm{ng} \mathrm{mL}^{-1}$ of $\mathrm{Ce}$ and $\mathrm{Ba}$ in $\mathrm{HCl} 1 \mathrm{M}$ following and optimising both the ratios ${ }^{140} \mathrm{Ce}^{16} \mathrm{O}^{+} /{ }^{140} \mathrm{Ce}^{+},{ }^{140} \mathrm{Ce}^{16} \mathrm{O}^{1} \mathrm{H}^{+}$ ${ }^{140} \mathrm{Ce}^{+},{ }^{138} \mathrm{Ba}^{16} \mathrm{O}^{+} /{ }^{138} \mathrm{Ba}^{+},{ }^{138} \mathrm{Ba}^{16} \mathrm{O}^{1} \mathrm{H}^{+} /{ }^{138} \mathrm{Ba}^{+}(<0.5-1.0 \%)$ and the ratios ${ }^{135} \mathrm{Ba}^{35} \mathrm{Cl}^{+} /{ }^{135} \mathrm{Ba}^{+},{ }^{135} \mathrm{Ba}^{37} \mathrm{Cl}^{+} /{ }^{135} \mathrm{Ba}^{+},{ }^{137} \mathrm{Ba}^{35} \mathrm{Cl}^{+} /{ }^{137} \mathrm{Ba}^{+}$, ${ }^{137} \mathrm{Ba}^{37} \mathrm{Cl}^{+} /{ }^{137} \mathrm{Ba}^{+},{ }^{138} \mathrm{Ba}^{35} \mathrm{Cl}^{+} /{ }^{138} \mathrm{Ba}^{+},{ }^{138} \mathrm{Ba}^{37} \mathrm{Cl}^{+/ 138} \mathrm{Ba}^{+}$, the higher amount of which was below $5 \%$. Successively we have determined, in our co-precipitated samples, the amount of barium residue and because this one was always lower than $500 \mathrm{pg} \mathrm{mL}^{-1}$, we have estimated an essentially negligible interference of barium [17].

Each solution was measured three times and ICP-MS analyses were carried out with a classical external calibration approach. It was carried out from 2.5 to $500 \mathrm{pg} \mathrm{mL}^{-1}$ for each investigated element using ${ }^{205} \mathrm{Tl}\left(1000 \mathrm{pg} \mathrm{mL}^{-1}\right)$ as an internal standard to compensate for any signal instability and all data in cps were normalised to the internal standard. The operating conditions are shown in Table 1.

\subsection{Reference material}

To the best of our knowledge, a seawater CRM certified for YLOID, $\mathrm{Zr}$ and $\mathrm{Hf}$, or at least one in which concentrations are given as information values, was not available. For this reason, according to the IUPAC technical report [18], nine aliquots (one liter each one) of two spiked seawater solutions, $A_{1}-A_{9}$ and $S_{1}-S_{9}$, with concentrations of $19.92 \pm 0.31 \mathrm{pg} \mathrm{mL}^{-1}$ for each studied element, were prepared to test and validate the proposed method. Solutions $A_{1}-A_{9}$ were made spiking nine procedural blanks $\left(P_{\mathrm{B} 1}-P_{\mathrm{B} 9}\right)$, which were obtained by twice treating natural seawater by coprecipitation with Fe-hydroxide until the concentrations of YLOID, $\mathrm{Zr}$ and $\mathrm{Hf}$ were below the instrumental quantification limit, while solutions $S_{1}-S_{9}$ were obtained by directly spiking seawater matrix.

\subsection{Co-precipitation procedure}

To test and validate the co-precipitation procedure, 1.000 $\pm 0.006 \mathrm{~mL}$ of the Fe standard solution $\left(1000 \pm 5 \mathrm{mg} \mathrm{mL}^{-1}\right.$, Merck,

Table 1

ICP-MS operating conditions and measurement parameters.

\begin{tabular}{|c|c|}
\hline RF power & $1550 \mathrm{~W}$ \\
\hline Sample uptake rate & $0.400 \mathrm{~mL} \mathrm{~min}^{-1}$ \\
\hline Coolant argon flow rate & $15 \mathrm{~L} \mathrm{~min}^{-1}$ \\
\hline Carrier argon flow rate & $0.80 \mathrm{~L} \mathrm{~min}^{-1}$ \\
\hline $\begin{array}{l}\text { Make-up argon flow } \\
\text { rate }\end{array}$ & $0.25 \mathrm{~L} \mathrm{~min}^{-1}$ \\
\hline Torch & Quartz \\
\hline Nebuliser & MicroMist $200 \mu \mathrm{L}$ \\
\hline $\begin{array}{l}\text { Sampler and skimmer } \\
\text { cones }\end{array}$ & Nickel \\
\hline Number of scans & 3 \\
\hline Ion lens settings & Adjusted daily to obtain max. signal intensity \\
\hline Washing time & $1 \mathrm{~min}\left(5 \% \mathrm{v} / \mathrm{v} \mathrm{HNO}_{3}\right)$ \\
\hline $\begin{array}{l}\text { Oxide }{ }^{156} \mathrm{CeO}^{+} /{ }^{140} \mathrm{Ce}^{+} \\
\text {ratio }\end{array}$ & $<0.8 \%$ \\
\hline $\begin{array}{l}\text { Double charged } \\
{ }^{70} \mathrm{Ce}^{++} /{ }^{140} \mathrm{Ce}^{+} \text {ratio }\end{array}$ & $<0.5 \%$ \\
\hline Measured isotope & $\begin{array}{l}{ }^{89} \mathrm{Y},{ }^{90} \mathrm{Zr},{ }^{139} \mathrm{La},{ }^{140} \mathrm{Ce},{ }^{141} \mathrm{Pr},{ }^{143} \mathrm{Nd},{ }^{147} \mathrm{Sm},{ }^{151} \mathrm{Eu},{ }^{158} \mathrm{Gd}, \\
{ }^{159} \mathrm{~Tb},{ }^{163} \mathrm{Dy},{ }^{165} \mathrm{Ho},{ }^{166} \mathrm{Er},{ }^{168} \mathrm{Tm},{ }^{172} \mathrm{Yb},{ }^{175} \mathrm{Lu},{ }^{178} \mathrm{Hf} .\end{array}$ \\
\hline Internal standard & ${ }^{205} \mathrm{Tl} 1000 \mathrm{pg} \mathrm{mL}^{-1}$ \\
\hline
\end{tabular}


Italy) was added to the nine aliquots of spiked seawater, $A_{\mathrm{i}}$ and $S_{\mathrm{i}}$, prepared as described in Section 2.3, then the $\mathrm{pH}$ was adjusted to $8.0 \pm 0.2$ using concentrated ammonia. To allow the homogenisation and precipitation of Fe-hydroxide, the samples were stirred for $2 \mathrm{~h}$ and then matured for two days. The samples were filtered on acid precleaned $0.45 \mu \mathrm{m}$ Nucleopore membrane and the Fe-hydroxide filtrate, washed with two portions of $25 \mathrm{~mL}$ of ultrapure water, was dissolved in $10 \mathrm{~mL}$ of $\mathrm{HCl} 6 \mathrm{mmol} \mathrm{mL}^{-1}$. Prior to measurement by ICP-MS, the solution was diluted six times with ultrapure water. The overall concentration factor of YLOID was approximately 16-fold.

\section{Results and discussion}

\subsection{Detection limit $(D L)$, quantification limit $(Q L)$ and procedural} $\operatorname{blank}\left(P_{B}\right)$

The first step of method validation was to verify the performances and the instrumental response of our ICP-MS. Calibration curves were calculated by regression analysis assuming a homogeneous variance of measured values over the whole investigated mass range (Table S1 supplementary data). The $R^{2}$ values, indicating linearity between signal and concentration, were considered satisfactory when equal to 0.998 or better for all of the isotopes monitored. Also, if there is still no full agreement between researchers, publishers, professional and statutory bodies, in general, the detection limit is the smallest amount of analyte concentration in the test sample that can be reliably distinguished from zero [19].

The instrumental detection limit (IDL) should be differentiated from the method detection limit (MDL). Indeed, the former is based on the measurement of a solution prepared as a calibration standard without the analyte, i.e. the calibration blank, while the latter, on the measurement of a solution, matching a real sample without analyte, subjected to the overall method, i.e. the procedural blank. IDL is often far smaller than an MDL and inappropriate for method validation because it does not take into account the matrix contribution and the entire analytical procedure.

To carry out IDL analyses, nine different aliquots of calibration blank ( $\mathrm{HCl} 1 \mathrm{mmol} \mathrm{mL}^{-1}$ ) were measured. The behaviour of the collected data were analysed according to Shapiro-Wilk's test $(P=0.05)$ to verify the normal distribution of obtained data and according to David's $(P=0.05)$, Grubb's $(P=0.05)$ and Huber's tests $(P=0.05)$ to verify the presence of outliers.

The IDL in pg $\mathrm{mL}^{-1}$, was calculated according to the following expressions: $y_{\mathrm{IDL}}=y_{\mathrm{B}}+3 s_{\mathrm{B}}$ and combined into $\mathrm{IDL}=y_{\mathrm{IDL}}$-intercept $\bullet b^{-1}$, where $y_{\mathrm{IDL}}$ is the detection limit in cps, $y_{\mathrm{B}}$ is the mean value of the signal of blank in cps, $s_{B}$ is the standard deviation of the blank measurements and $b$ is the slope of the calibration curve.

Instrument quantification limit (IQL), which is defined as the smallest amount of analyte in a test sample that can be quantified with suitable precision and accuracy under previously established method conditions, was calculated according to the following expressions: $y_{\mathrm{IQL}}=y_{\mathrm{B}}+10 \mathrm{~s}_{\mathrm{B}}$ and $\mathrm{IQL}=y_{\mathrm{IQL}}$-intercept $\cdot b^{-1}$ where $y_{\mathrm{B}}, s_{\mathrm{B}}, b$ are as above and $y_{\mathrm{IQL}}$ is the quantification limit in cps and IQL in pg $\mathrm{mL}^{-1}$ (Table S2 supplementary data).

All of the results highlight the very good performances of our ICP-MS. In particular, the instrumental DL and QL were comparable or lower than the mean concentration estimated in natural seawater for all elements and therefore, for most of the elements, the performances of our ICP-MS were suitable for a correct quantification also without a pre-concentration method if there are no interferences from matrix.

The choice of an appropriate procedural blank in trace and ultra-trace analytical determination is paramount to assess contaminations and matrix interferences, mostly if the concentrations are close to the MQL. To obtain MDL and MQL, the calibration blank (nitric or hydrochloric acid solutions) or ultrapure water were not taken into account because they could not estimate matrix interferences. On the other hand, we discarded the idea of synthetic seawater because not all salts of ultrapure grade were available for preparation, which, consequently, could generate more and/or different interferences than a real matrix.

For these reasons, the procedural blank was obtained by twice subjecting nine aliquots of real seawater to the entire method. The amounts determined in the precipitate obtained at the second coprecipitation procedures ( $\mathrm{B}^{\prime}$ solution) are close or less than IQL for ${ }^{90} \mathrm{Zr}\left(40.88 \pm 6.83 \mathrm{pg} \mathrm{mL}^{-1}\right)$ and for the elements from ${ }^{147} \mathrm{Sm}$ $\left(3.18 \pm 0.85 \mathrm{pg} \mathrm{mL}^{-1}\right)$ to ${ }^{178} \mathrm{Hf}\left(1.02 \pm 0.84 \mathrm{pg} \mathrm{mL}^{-1}\right)$; in contrast, concentrations for the elements from ${ }^{89} \mathrm{Y}$ to ${ }^{146} \mathrm{Nd}$ were slightly higher than IQL. On these considerations, we supposed that in the resulting solution the analytes were in concentration below the quantification limit and hence we did not carry out further coprecipitations.

Method detection and quantification limits calculated as above, with mean values and standard deviations in $\mathrm{pg} \mathrm{mL}^{-1}$ of procedural blank, are reported in Table 2.

The achieved values were significantly higher than IDL and IQL, due to matrix contribution. Comparing our data to previous works $[8,10,20]$, describing methods on the determination of YLOID, $\mathrm{Zr}$ and Hf in seawater, we obtained higher procedural blank, MDL and MQL values, which, we believe, were also due to the different analytical methods employed, but essentially due to the different matrix chosen as procedural blank.

\subsection{Recovery}

In order to evaluate the accuracy of the entire procedure, the amount of recovery was calculated on YLOID, $\mathrm{Zr}$ and $\mathrm{Hf}$ spiked seawater solutions $A_{\mathrm{i}}$ and $S_{\mathrm{i}}$, as the ratio between analysed and spiked concentrations for each element. Data of procedural blank and seawater without YLOID, $\mathrm{Zr}$ and $\mathrm{Hf}$ were subtracted from sample analysis values in the calculation of recovery amounts.

At the low concentration of seawater in our experiment ( $\sim 20 \mathrm{ng} \mathrm{L}^{-1}$ ) we consider that the recovery obtained for $\mathrm{Zr}$ and Hf were influenced by the speciation of the two elements present as $\mathrm{Zr}(\mathrm{OH})_{5}{ }^{-}$and $\mathrm{Hf}(\mathrm{OH})_{5}{ }^{-}$and after the co-precipitation on $\mathrm{Fe}$ hydroxide essentially as $\mathrm{Zr}$ and $\mathrm{Hf}$ oxy-hydroxide. We used $\mathrm{HCl}$

Table 2

Mean values $\left(C_{\mathrm{B}}, C_{\mathrm{B}^{\prime}}\right)$ and standard deviation $\left(s_{\mathrm{B}}, S_{\mathrm{B}^{\prime}}\right)$ of procedural blanks ( $B$ and $B^{\prime}$ ), method detection limit (MDL) and method quantification limit (MOL) all in pg mL ${ }^{-1}$.

\begin{tabular}{|c|c|c|c|c|c|c|}
\hline & \multicolumn{2}{|l|}{ B } & \multicolumn{2}{|l|}{$B^{\prime}$} & \multicolumn{2}{|c|}{ method } \\
\hline & $C_{\mathrm{B}}$ & $s_{\mathrm{B}}$ & $C_{\mathrm{B}^{\prime}}$ & $s_{\mathrm{B}^{\prime}}$ & MDL & MQL \\
\hline${ }^{89} \mathrm{Y}$ & 337 & 13 & 15.7 & 3.7 & 27.2 & 54.4 \\
\hline${ }^{90} \mathrm{Zr}$ & 296.0 & 6.6 & 40.9 & 6.8 & 61.0 & 109.6 \\
\hline${ }^{139} \mathrm{La}$ & 2264 & 715 & 124 & 97 & 408.3 & 1076.6 \\
\hline${ }^{140} \mathrm{Ce}$ & 190.4 & 6.9 & 42.3 & 16.1 & 92.3 & 208.6 \\
\hline${ }^{141} \mathrm{Pr}$ & 24.87 & 0.57 & 5.2 & 2.0 & 11.5 & 25.9 \\
\hline${ }^{143} \mathrm{Nd}$ & 109.2 & 5.4 & $13.9_{5}$ & 4.6 & 28.4 & 62.1 \\
\hline${ }^{147} \mathrm{Sm}$ & $25.3_{5}$ & 1.1 & 3.18 & 0.85 & 5.3 & 11.6 \\
\hline${ }^{151} \mathrm{Eu}$ & 6.40 & 0.04 & 1.40 & 0.62 & 3.2 & 7.5 \\
\hline${ }^{158} \mathrm{Gd}$ & 50.5 & 3.6 & 5.1 & 2.0 & 11.9 & 26.3 \\
\hline${ }^{159} \mathrm{~Tb}$ & 4.66 & 0.22 & 1.30 & 0.67 & 3.5 & 8.2 \\
\hline${ }^{163}$ Dy & 28.5 & 1.2 & 3.5 & 1.7 & 8.3 & 20.2 \\
\hline${ }^{165} \mathrm{Ho}$ & 6.52 & 0.20 & 1.30 & 0.71 & 2.1 & 4.8 \\
\hline${ }^{166} \mathrm{Er}$ & 19.65 & 0.63 & 2.3 & 1.3 & 3.7 & 7.7 \\
\hline${ }^{169} \mathrm{Tm}$ & 2.77 & 0.14 & 2.21 & 0.84 & 4.5 & 10.1 \\
\hline${ }^{172} \mathrm{Yb}$ & 17.00 & 0.47 & $2.1_{5}$ & 1.2 & 6.0 & 14.2 \\
\hline${ }^{175} \mathrm{Lu}$ & 3.05 & 0.15 & 1.04 & 0.44 & 2.9 & 7.5 \\
\hline${ }^{178} \mathrm{Hf}$ & 2.37 & 0.27 & 1.02 & 0.84 & 3.8 & 9.7 \\
\hline
\end{tabular}


$6 \mathrm{M}$ to completely dissolve on the membrane, the Fe hydroxide co-precipitated but it is well known that to better dissolve and maintain $\mathrm{Zr}$ and $\mathrm{Hf}$ in solution the addition of HF is useful. We have tried to optimise this way but the low reproducibility of the results convinced us to leave it and to accept the lower but more reproducible ones. With higher $\mathrm{Zr}$ and $\mathrm{Hf}$ concentrations $\left(\sim 100 \mathrm{pg} \mathrm{mL}^{-1}\right)$ the results, with only $\mathrm{HCl} 6 \mathrm{M}$ and without $\mathrm{HF}$, were better but without utility for our studies on seawater where the $\mathrm{Zr}$ and $\mathrm{Hf}$ concentration are very low. On the other hand, the stability problem for YLOID is negligible in the final acid solution by $\mathrm{HCl} 1 \mathrm{M}$, as it is in our case.

We think that the recovery values ( $>100 \%$ ) for the YLOID in our experimentation can be due to both low concentration used as spike and seawater, YLOID depleted or not, used as procedural blank. In fact, frequently in literature, more concentrated spikes (100-1000 $\left.\mathrm{ng} \mathrm{L}^{-1}\right)[11,21]$ and procedural blank made with ultrapure water or $\mathrm{HNO}_{3}$ diluted solution [12,22] were used. Higher spike YLOID concentrations improve the precision of the overall procedure and/or use of procedural blank, very different from seawater, cannot consider the matrix effect and improve the repeatability precision of the determinations drastically. We have carried out in the early stage of the validation procedure several trial with more concentrated spike $\left(50 \mathrm{pg} \mathrm{mL}^{-1}\right)$ in seawater with the same procedural blank and we also have obtained recovery percentage in the range 95-100, but we think that the extrapolation of this result to NASS-6 or other seawater CRMs analysis to be a coarse error.

After controls according to Shapiro-Wilk's $(P=0.05)$, David's $(P=0.05)$, Grubb's $(P=0.05)$ and Huber's tests $(P=0.05)$, the mean value of the nine replicates $\left(A_{\mathrm{m}}\right.$ and $\left.S_{\mathrm{m}}\right)$ and the standard deviations $\left(s_{\mathrm{A}}\right.$ and $s_{\mathrm{S}}$ ) (Table 3 ) were calculated.

These values were higher than MQL and into the linearity range of the calibration adopted. Mean values, standard deviations, and recovery percentage (in the range $75-108 \%$ and $88-117 \%$ ), with a good repeatability ( $<10 \%$ ) for $A_{\mathrm{m}}$ and $S_{\mathrm{m}}$ solutions were listed in Tables 4 and 5, respectively. Subjecting both $A_{\mathrm{i}}$ and $S_{\mathrm{i}}$ solutions to the entire method, matrix contribution and role of interferences were highlighted; in spiked natural seawater, $S$ solutions, we obtained values slightly higher than $A$ solution, which confirmed that our procedural blank also brought about significant differences mostly in ultra-trace analytical determination, despite the high likeness to the real matrix.

Table 3

Mean value $\left(C_{\mathrm{A}}, C_{\mathrm{S}}\right)$, standard deviation $\left(s_{\mathrm{A}}, s_{\mathrm{S}}\right)$ in $\mathrm{pg} \mathrm{mL}^{-1}$ and relative standard deviation percentage (RSD\%) of the nine replicates obtained by the co-precipitation of $A_{\mathrm{i}}$ and $S_{\mathrm{i}}$ solutions.

\begin{tabular}{|c|c|c|c|c|c|c|}
\hline & \multicolumn{3}{|c|}{ A solutions } & \multicolumn{3}{|c|}{$S$ solution } \\
\hline & $C_{\mathrm{A}}$ & $s_{\mathrm{A}}$ & RSD \% & $\mathrm{C}_{\mathrm{S}}$ & $s_{\mathrm{S}}$ & RSD \% \\
\hline${ }^{89} \mathrm{Y}$ & 332 & 12 & 4 & 368 & 17 & 5 \\
\hline${ }^{90} \mathrm{Zr}$ & 248 & 14 & 6 & 325 & 16 & 5 \\
\hline${ }^{139} \mathrm{La}$ & 348 & 50 & 14 & 390 & 30 & 8 \\
\hline${ }^{140} \mathrm{Ce}$ & 336 & 16 & 5 & 370 & 20 & 5 \\
\hline${ }^{141} \mathrm{Pr}$ & 342 & 16 & 5 & 316 & 2 & 1 \\
\hline${ }^{143} \mathrm{Nd}$ & 340 & 16 & 5 & 362 & 16 & 5 \\
\hline${ }^{147} \mathrm{Sm}$ & 354 & 5 & 1 & 372 & 11 & 3 \\
\hline${ }^{151} \mathrm{Eu}$ & 342 & 16 & 5 & 374 & 10 & 3 \\
\hline${ }^{158} \mathrm{Gd}$ & 348 & 15 & 4 & 373 & 19 & 5 \\
\hline${ }^{159} \mathrm{~Tb}$ & 344 & 17 & 5 & 370 & 10 & 3 \\
\hline${ }^{163}$ Dy & 340 & 17 & 5 & 364 & 10 & 3 \\
\hline${ }^{165} \mathrm{Ho}$ & 342 & 16 & 5 & 365 & 9 & 3 \\
\hline${ }^{166} \mathrm{Er}$ & 344 & 16 & 5 & 366 & 9 & 3 \\
\hline${ }^{169} \mathrm{Tm}$ & 342 & 17 & 5 & 362 & 10 & 3 \\
\hline${ }^{172} \mathrm{Yb}$ & 334 & 18 & 5 & 356 & 10 & 3 \\
\hline${ }^{175} \mathrm{Lu}$ & 343 & 17 & 5 & 362 & 9 & 3 \\
\hline${ }^{178} \mathrm{Hf}$ & 337 & 16 & 5 & 293 & 15 & 5 \\
\hline
\end{tabular}

To verify whether the results obtained for $A$ and $S$ solutions can be accounted for by random or systematic errors, a $t$-test was employed. In order to decide whether the difference between two sample means, $A$ and $S$, was significant, that is to test the null hypothesis, $H_{0}=\mu_{\mathrm{A}}=\mu_{\mathrm{S}}$, the $t_{\text {calc }}$ was calculated for each element (Table S3 supplementary data)

$t_{\text {calc }}=\frac{\left|A_{\mathrm{m}}-S_{\mathrm{m}}\right|}{s \sqrt{\left(1 / n_{\mathrm{a}}\right)+\left(1 / n_{\mathrm{s}}\right)}}$

where $n_{\mathrm{a}}$ and $n_{\mathrm{s}}$ are the samples size and $s$, assuming that the samples are drawn from populations with equal standard deviation, was calculated from

$s^{2}=\frac{\left(n_{\mathrm{A}}-1\right) s_{\mathrm{A}}^{2}+\left(n_{\mathrm{S}}-1\right) s_{\mathrm{S}}^{2}}{n_{\mathrm{A}}+n_{\mathrm{S}}-2}$

if $t_{\text {calc }}$ exceeds the critical value $t_{\text {th }}$ (for a confidence level of 0.05 and degree of freedom $\nu=n_{\mathrm{a}}+n_{\mathrm{s}}-2$ as reported in Supplementary Table S3) the null hypothesis is rejected.

Because $t_{\text {calc }}>t_{\text {th }}$ for all elements, meaning that the null hypothesis is rejected, differences between $A$ and $S$ solutions are due to systematic errors, confirming that the two matrices are significantly different. On the other hand, according to Gonzales [23], recoveries were acceptable in the range $40-120 \%$ if the analyte level was less than $1 \mathrm{ng} \mathrm{mL}^{-1}$. Therefore, following these criteria, analyses of results for $A$ and $S$ solutions demonstrated that the investigated elements were almost completely recovered after co-precipitation in a seawater matrix.

Successively we also decided to evaluate recovery statistically by $t$ test, using the following equation:

$t_{\text {calc }}=\frac{\left|C_{\text {spiked }}-x_{\mathrm{m}}\right|}{\sqrt{\left(s_{\mathrm{r}}^{2} / N\right)+s_{\text {spiked }}^{2}}} \leq t_{\text {th }(p=0.05, \nu)}$

where $x_{\mathrm{m}}$ is the mean value, $s_{\mathrm{r}}$ is the standard deviation of repeatability, $C_{\text {spiked }}$ is the concentration of spiked solution $\left(19.92 \pm 0.31 \mathrm{pg} \mathrm{mL}^{-1}\right), s_{\text {spiked }}$ is the standard deviation and $t_{\mathrm{th}}$ $(p=0.05, \nu)$ is the theoretical value of $t$ with a confidence level of 0.05 and a degree of freedom value, $\nu$, calculated by

$\nu=\frac{\left(\left(s_{\mathrm{r}}^{2} / N\right)+u_{\text {spiked }}^{2}\right)^{2}}{\left(s_{\mathrm{r}}^{2} / N\right)^{2}}(N-1)$

where $N$ is the number of replicates.

The $t_{\text {calc }}$ value, the degree of freedom and $t_{\mathrm{th}}$ for $A_{\mathrm{m}}$ and $S_{\mathrm{m}}$ solution are listed in Tables S4 and S5 supplementary data, respectively.

Table 4

Mean concentration values $\left(A_{\mathrm{m}}\right)$ and standard deviations $\left(s_{\mathrm{Am}}\right)$ in $\mathrm{pg} \mathrm{mL}^{-1}$, relative standard deviations percentage (RSD\%), repeatability limits $(r)$, recovery percentages (Rec\%) and standard deviations of recovery percentage $\left(s_{\text {Rec\% }}\right)$ of $A$ solutions.

\begin{tabular}{lllllrr}
\hline & $A_{\mathrm{m}}$ & $S_{\text {Am }}$ & RSD $\%$ & \multicolumn{1}{l}{$r$} & Rec\% & $S_{\text {Rec\% }}$ \\
\hline${ }^{89} \mathrm{Y}$ & 20.08 & 0.68 & 3 & 2.37 & 101 & 5 \\
${ }^{90} \mathrm{Zr}$ & 14.94 & 0.65 & 4 & 2.54 & 75 & 7 \\
${ }^{139} \mathrm{La}$ & 21.05 & 2.0 & 10 & 9.92 & 106 & 21 \\
${ }^{140} \mathrm{Ce}$ & 20.24 & 0.68 & 3 & 2.55 & 102 & 5 \\
${ }^{141} \mathrm{Pr}$ & 21.06 & 0.75 & 3 & 2.47 & 106 & 5 \\
${ }^{143} \mathrm{Nd}$ & 20.95 & 0.82 & 4 & 2.77 & 105 & 5 \\
${ }^{147} \mathrm{Sm}$ & 21.12 & 0.27 & 1 & 1.00 & 106 & 2 \\
${ }^{151} \mathrm{Eu}$ & 21.05 & 0.71 & 3 & 2.33 & 106 & 4 \\
${ }^{158} \mathrm{Gd}$ & 21.42 & 0.92 & 4 & 3.03 & 108 & 6 \\
${ }^{159} \mathrm{~Tb}$ & 21.18 & 0.75 & 4 & 2.46 & 106 & 5 \\
${ }^{163} \mathrm{Dy}$ & 20.93 & 0.73 & 4 & 2.41 & 105 & 5 \\
${ }^{165} \mathrm{Ho}$ & 21.07 & 0.72 & 3 & 2.35 & 106 & 5 \\
${ }^{166} \mathrm{Er}$ & 21.18 & 0.77 & 4 & 2.52 & 106 & 5 \\
${ }^{169} \mathrm{Tm}$ & 21.06 & 0.71 & 3 & 2.32 & 106 & 5 \\
${ }^{172} \mathrm{Yb}$ & 20.58 & 0.70 & 3 & 2.28 & 103 & 5 \\
${ }^{175} \mathrm{Lu}$ & 21.11 & 0.75 & 4 & 2.46 & 106 & 5 \\
${ }^{178} \mathrm{Hf}$ & 20.77 & 0.87 & 4 & 2.84 & 104 & 6 \\
\hline
\end{tabular}


Table 5

Mean concentration values $\left(S_{\mathrm{m}}\right)$ and standard deviations $\left(s_{\mathrm{Sm}}\right)$ in $\mathrm{pg} \mathrm{mL}^{-1}$, relative standard deviations percentage (RSD\%), repeatability limits $(r)$, recovery percentages (Rec\%) and standard deviations of recovery percentage $\left(s_{\text {Rec\% }}\right)$ of $S$ solutions.

\begin{tabular}{lllllrc}
\hline & $S_{\mathrm{m}}$ & $S_{\mathrm{Sm}}$ & RSD & $r$ & Rec\% & $S_{\text {Rec\% }}$ \\
\hline${ }^{89} \mathrm{Y}$ & 21.85 & 1.03 & 5 & 6.47 & 110 & 10 \\
${ }^{90} \mathrm{Zr}$ & 19.48 & 0.98 & 5 & 6.25 & 98 & 9 \\
${ }^{139} \mathrm{La}$ & 23.4 & 1.8 & 8 & 7.15 & 117 & 9 \\
${ }^{140} \mathrm{Ce}$ & 22.21 & 1.19 & 5 & 5.87 & 111 & 9 \\
${ }^{141} \mathrm{Pr}$ & 23.04 & 0.13 & 1 & 0.55 & 116 & 1 \\
${ }^{143} \mathrm{Nd}$ & 21.73 & 0.97 & 4 & 4.14 & 109 & 6 \\
${ }^{147} \mathrm{Sm}$ & 22.33 & 0.65 & 3 & 2.26 & 112 & 4 \\
${ }^{151} \mathrm{Eu}$ & 22.44 & 0.61 & 3 & 2.02 & 113 & 3 \\
${ }^{158} \mathrm{Gd}$ & 22.16 & 0.62 & 3 & 1.89 & 111 & 3 \\
${ }^{159} \mathrm{~Tb}$ & 22.04 & 0.57 & 3 & 1.98 & 111 & 3 \\
${ }^{163} \mathrm{Dy}$ & 21.88 & 0.60 & 3 & 1.81 & 110 & 3 \\
${ }^{165} \mathrm{Ho}$ & 21.94 & 0.55 & 2 & 1.85 & 110 & 3 \\
${ }^{166} \mathrm{Er}$ & 21.73 & 0.54 & 2 & 1.95 & 109 & 3 \\
${ }^{169} \mathrm{Tm}$ & 21.36 & 0.59 & 3 & 2.13 & 107 & 3 \\
${ }^{172} \mathrm{Yb}$ & 21.71 & 0.62 & 3 & 1.85 & 109 & 3 \\
${ }^{175} \mathrm{Lu}$ & 17.62 & 0.56 & 3 & 2.93 & 88 & 5 \\
${ }^{178} \mathrm{Hf}$ & 17.76 & 0.89 & 5 & 2.93 & 89 & 4 \\
\hline
\end{tabular}

When $t_{\text {calc }}<t_{\text {th }}$ the recovery can be assumed equal to unity, i.e. $100 \%$. The results indicate that in $A_{\mathrm{i}}$ solutions ${ }^{89} \mathrm{Y},{ }^{139} \mathrm{La},{ }^{140} \mathrm{Ce}$, ${ }^{146} \mathrm{Nd},{ }^{163} \mathrm{Dy},{ }^{172} \mathrm{Yb}$ and ${ }^{178} \mathrm{Hf}$ and in $S_{\mathrm{i}}$ solutions ${ }^{90} \mathrm{Zr}$ are fully recovered, being $t_{\text {calc }}<t_{\text {th }}$. Except for ${ }^{90} \mathrm{Zr}$ in $A_{\mathrm{i}}$ solutions, we believe that negative results obtained for the other elements were due to mathematical problems and not chemical ones, for which, paradoxically, if the difference between mean value and $C_{\text {spiked }}$ is small and the standard deviation is very low in $t_{\text {calc }}$ formula, the ratio will be large.

In this study, as indicated above, we achieved the same recovery for all elements when spiking both the procedural blank and the seawater sample. Furthermore, the data are in agreement with literature values obtained using other analytical methods [20,21].

\subsection{Natural water reference materials}

To the best of our knowledge, there are no seawater Certified Reference Materials for YLOID, Zirconium and Hafnium all together. Only a few published data obtained by treating seawater CRM (CASS-4, NASS-5) are available, but, unfortunately, the comparison is not possible because CASS-4 and NASS-5 are no longer commercially available.

After validating the method as previously discussed, we decided to apply it to three aliquots of 1 L NASS-6, which is a CRM that the National Research Council of Canada has distributed in substitution of NASS-5.

The analytical results for the natural water CRM are summarised in Table 6, with standard deviations of the set of our replicate measurements, while Post-Archaean Australian shale (PAAS)-normalised [24] YLOID patterns are shown in Fig. 1. Generally, the seawater YLOID pattern is characterised by various anomalies in the shale-normalised pattern: La is present at higher concentration than the neighbouring YLOID, Y is highly enriched over Ho and Eu, Gd and Lu are also usually over-abundant, but to a much lesser extent [25]. The resulting anomalies can be quantified by comparing the measured value to that extrapolated from neighbouring elements of "normal" abundance (i.e., the ratio Ln/ Ln* where Ln represents a YLOID element). The choice of normalising element is important and, as reported by Lawrence and Kamber [26], we calculated Ln/Ln* assuming constant the ratio of neighbouring elements but avoiding other anomalous elements in the calculation. Therefore, both La* and Ce* were calculated from $\mathrm{Pr}$ and Nd. As reported always by Lawrence and Kamber [26] "The
Table 6

Measured YLOID, $\mathrm{Zr}$ and $\mathrm{Hf}$ concentrations and standard deviations (in $\mathrm{pg} \mathrm{mL}^{-1}$ ) for blank and NASS-6 seawater reference material.

\begin{tabular}{|c|c|c|c|c|}
\hline & \multicolumn{2}{|l|}{ Blank } & \multicolumn{2}{|l|}{ NASS-6 } \\
\hline & $\mathrm{pg} \mathrm{ml} \mathrm{l}^{-1}$ & $s$ & $\mathrm{pg} \mathrm{ml}{ }^{-1}$ & $s$ \\
\hline${ }^{89} \mathrm{Y}$ & 0.34 & 0.03 & 17 & 1 \\
\hline${ }^{90} \mathrm{Zr}$ & 1.9 & 0.3 & 23 & 3 \\
\hline${ }^{139} \mathrm{La}$ & 0.621 & 0.005 & 12.7 & 0.4 \\
\hline${ }^{140} \mathrm{Ce}$ & 0.48 & 0.01 & 6.2 & 0.3 \\
\hline${ }^{141} \mathrm{Pr}$ & 0.01 & 0.02 & 2 & 2 \\
\hline${ }^{143} \mathrm{Nd}$ & 0.10 & 0.04 & 6 & 3 \\
\hline${ }^{147} \mathrm{Sm}$ & $<$ IDL & - & 0.81 & 0.07 \\
\hline${ }^{151} \mathrm{Eu}$ & $<$ IDL & - & 0.24 & 0.04 \\
\hline${ }^{158} \mathrm{Gd}$ & 0.03 & 0.03 & 1 & 2 \\
\hline${ }^{159} \mathrm{~Tb}$ & 0.01 & 0.01 & 0.2 & 0.2 \\
\hline${ }^{163}$ Dy & 0.22 & 0.02 & 1.6 & 0.2 \\
\hline${ }^{165} \mathrm{Ho}$ & $<$ IDL & - & 0.31 & 0.02 \\
\hline${ }^{166} \mathrm{Er}$ & 0.14 & 0.02 & 1.7 & 0.3 \\
\hline${ }^{169} \mathrm{Tm}$ & 0.03 & 0.01 & 0.24 & 0.09 \\
\hline${ }^{172} \mathrm{Yb}$ & 0.062 & 0.007 & 1.3 & 0.2 \\
\hline${ }^{175} \mathrm{Lu}$ & 0.052 & 0.009 & 0.26 & 0.04 \\
\hline${ }^{178} \mathrm{Hf}$ & $<$ IDL & - & 0.9 & 0.1 \\
\hline
\end{tabular}

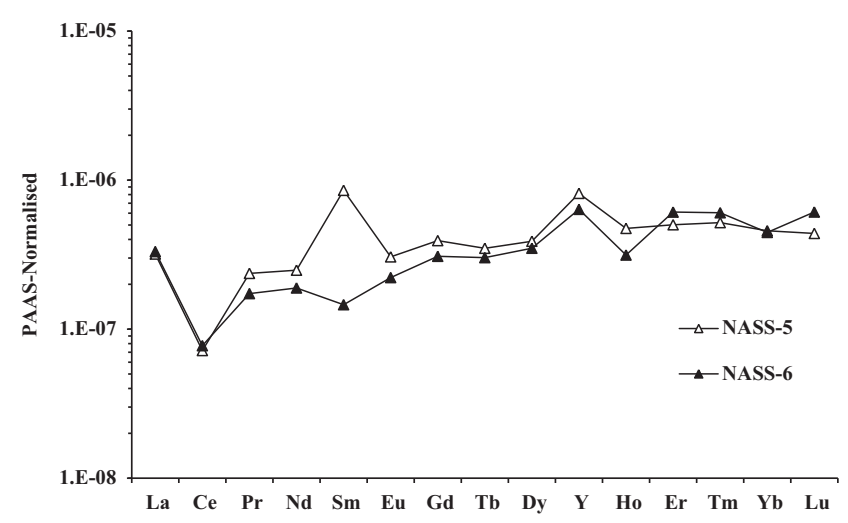

Fig. 1. PASS normalised YLOID pattern for NASS-6 seawater reference material.

main purpose of this exercise in the context of method evaluation is that the reproducibility of the calculated YLOID anomalies is a strong reflection of data quality (but not an independent measure)". Calculated anomalies are listed in Table 7. A value greater than 1 is considered a positive anomaly while a value less than $1 \mathrm{a}$ negative anomaly. The anomalies obtained with our data agree with the known seawater patterns [27]. There is a strong positive $\mathrm{La}$ and $\mathrm{Y}$ anomaly and a strong negative Ce anomaly in the samples. We also observed weak positive Gd anomalies. These values are consistent with theoretical considerations [28]. The Eu anomaly calculated from $\mathrm{Tb}$ and $\mathrm{Dy}$ is indistinguishable from unity. Because the prime purpose of seawater YLOID studies is to understand and trace exactly the extent of YLOID anomalies, the validation of the analytical protocol that is able to obtain reproducible values is paramount. Our method was capable of easily resolving the $\mathrm{La}, \mathrm{Ce}$ and $\mathrm{Y}$ anomalies, and also consistently resolved the smaller Gd anomaly. A comparison of the NASS-6 data with those of Lawrence et al. [10] for NASS-5 shows that the calculated anomalies agreed: the La anomaly was 2.3 compared with 1.65 , Ce was 0.48 compared with 0.34 , and Gd was 1.18 compared with 1.19 .

Contrary to the observed and variously interpreted large Sm anomaly in reference materials comparing oceanic behaviour, NASS-6 shows a more common slightly negative Sm anomaly (0.64 compared with 2.49). 
Table 7

YLOID anomalies calculated from PASS-normalised values.

\begin{tabular}{llc}
\hline & $\mathrm{Ln}^{*}$ & NASS-6 \\
\hline La anomaly & $\mathrm{Pr}^{3} / \mathrm{Nd}^{2}$ & 2.28 \\
Ce anomaly & $\mathrm{Pr}^{2} / \mathrm{Nd}^{2}$ & 0.49 \\
Sm anomaly & $\mathrm{Nd}^{3} / \mathrm{Pr}^{2}$ & 0.65 \\
Eu anomaly & $\mathrm{Tb}^{3} / \mathrm{Dy}$ & 0.98 \\
Gd anomaly & $\mathrm{Tb}^{2} / \mathrm{Tm}$ & 1.18 \\
Y/Ho & $\mathrm{Y} / \mathrm{Ho}$ & 55.19 \\
\hline
\end{tabular}

$\mathrm{Y} / \mathrm{Ho}$ is the mass ratio, without normalisation.

It is probable that NASS-6, a new reference material, is not affected by the contamination that, according to authors, was responsible for the Sm over-abundance in CASS-2, CASS-3, NASS-2, NASS-4 and NASS-5 [29-34].

On the other hand, the obtained values on NASS-6, $22.73 \pm 3.32$ and $0.063 \pm 0.008 \mathrm{pg} \mathrm{mL}^{-1}$, for $\mathrm{Zr}$ and $\mathrm{Hf}$ respectively, agree very well with those reported for the Atlantic Ocean by different authors $[35,36]$.

\section{Conclusion}

To implement the quality criteria that allows one to monitor and demonstrate the performance characteristics of methods, we have validated an analytical methodology for a pre-concentration technique to ensure the simultaneous quantitative recovery of YLOID, $\mathrm{Zr}$ and $\mathrm{Hf}$ content in a complex matrix like seawater using QICP-MS. The working range and its linearity, the detection and quantification limits, recoveries, precision as repeatability and accuracy were analysed.

All of the results show the very good performances of ICP-MS In particular, the instrumental DL and QL were comparable or lower than the mean concentration estimated in natural seawater for all elements. The method was accurate and precise, and the investigated elements were almost completely recovered after coprecipitation in the seawater matrix (in the range 75-117\%), with a good repeatability $(<10 \%)$. The YLOID, zirconium and hafnium concentrations of the seawater reference material NASS-6 are reported for the first time.

The concentrations obtained for NASS- 6 are consistent with the most reliable literature data. Shale-normalised YLOID patterns for NASS-6 are consistent with the known seawater patterns.

As YLOID, $\mathrm{Zr}$ and $\mathrm{Hf}$ were never simultaneously investigated in the marine natural system, this validated method allows to obtain results about YLOID, $\mathrm{Zr}$ and $\mathrm{Hf}$ distributions in seawater to more deeply understand the marine and geochemical behaviour of these elements. Accordingly, we propose our data with related uncertainties for all naturally occurring YLOID, $\mathrm{Zr}$ and $\mathrm{Hf}$ to be considered for future compilations and reference values.

\section{Appendix A. Supplementary materials}

Supplementary data associated with this article can be found in the online version at http://dx.doi.org/10.1016/j.talanta.2013.08.019.

\section{References}

[1] D.S. Alibo, Y. Nozaki, Deep-Sea Res. 51 (2003) 47-62.

[2] P. Censi, L.A. Randazzo, P. Zuddas, F. Saiano, P. Aricò, S. Andò, J. Volcanol Geoterm. Res. 193 (2010) 106-116.

[3] P. Moller, P Dulski, J. Luck, Spectrochim. Acta 47 (1999) 1379-1387.

[4] P. Censi, P. Zuddas, D. Larocca, F. Saiano, F. Placenti, A. Bonanno, Chem. Ecol. 23 (2007) 139-153.

[5] M.L Firdaus, K. Norisuye, Y. Nakagawa, S. Nakatsuka, Y. Sohrin, J. Oceanogr. 64 (2008) 247-257.

[6] M. Bau, Geochim. Cosmochim., Acta 63 (1999) 67-77.

[7] M.B. Shabani, T. Akagi, H. Shimizu, A. Masuda., Anal. Chem. (1990)2714-2790.

[8] B.A. McKelvey, K.J. Orians, Mar. Chem. 60 (1998) 245-255.

[9] I. Kim, S. Kim, G. Kim, Aquat. Geochem. 16 (2010) 611-620.

[10] M.G. Lawrence, B.S. Kamber, Geostand. Geoanal. Res. 31 (2007) 95-103.

[11] S. Hirata, T. Kajiya, M. Aihara, K. Honda, O. Shikino, Talanta 58 (2002) $1185-1194$.

[12] T. Kajiya, M. Aihara, S. Hirata, Spectrochim. Acta, Part B 59 (2004) 543-550.

[13] G. Bayon, D. Birot, C. Bollinger, J.A. Barrat, Geostand. Geoanal. Res. 35 (2011) 145-153.

[14] D. Rahmi, Y. Zhu, E. Fujimori, T. Umemura, H. Haraguchi, Talanta 72 (2007) 600-606.

[15] M.A. Tracoso, M.M. Correia dos Santos, M.L.Simões Gonçalves, Accredit. Qual Assur. 8 (2003) 323-333.

[16] BIPM, IEC, IFCC, ILAC, IUPAC, IUPAP, ISO, OIML (2012) The international vocabulary of metrology-basic and general concepts and associated terms (VIM), 3rd edn. JCGM 200:2012. www.bipm.org/vim.

[17] P. Dulski, J. Fresenius, Anal. Chem. 350 (1994) 194-203.

[18] M. Thompson, S.L.R. Ellison, A. Fajgelj, P. Willetts, R. Wood, Pure Appl. Chem. 71 (1999) 337-348.

[19] M. Thomson, S.L.R. Ellison, R. Wood, Pure Appl. Chem. 74 (2002) 835-855.

[20] M.L. Firdaus, K. Norisuye, T. Sato, S. Urushihara, Y. Nakagawa, S. Umetani, Y. Sohrin, Anal. Chim. Acta 583 (2007) 296-302.

[21] Y. Zhu, A. Itoh, E. Fujimori, T. Umemura, H. Haraguchi, J. Alloys Compd. 408 (2006) 985-988.

[22] Y. Zhu, T. Umemura, H. Haraguchi, K. Inagaki, K. Chiba, Talanta 78 (2009) $891-895$.

[23] A.G. Gonzalez, A.M. Herrador, Trends Anal. Chem. 26 (2007) 227-238.

[24] S.R. Taylor, S.M. McLennan, The Continental Crust: Its Composition and Evolution, Blackwell Scientific, Oxford, 1985.

[25] M. Bau, P. Moller, P. Dulski, Mar. Chem. 56 (1997) 123-131.

[26] M.G. Lawrence, B.S. Kamber, Mar. Chem. 100 (2006) 147-161.

[27] J. Zhang, Y. Nozaki, Geochim. Cosmochim. Acta 60 (1996) 4631-4644.

[28] R.H. Byrne, J.H. Lee, Mar. Chem. 44 (1993) 121-130.

[29] K.E. Jarvis, J.G. Williams, E. Alcantara, J.D. Wills, J. Anal. At. Spectrom. 11 (1996) 917-922.

[30] T. Yabutani, K. Chiba, H. Haraguchi, Bull. Chem. Soc. Jpn 74 (2001) 31-38.

[31] L. Halicz, I. Gavrieli, E. Dorfman, J. Anal. At. Spectrom. 11 (1996) 811-814.

[32] S.N. Willie, R.E. Sturgeon, Spectrochim. Acta, Part B 56 (2001) 1707-1716.

[33] T.J. Shaw, T. Duncan, B. Schnetger, Anal. Chem. 75 (2003) 3396-3403.

[34] M.G. Lawrence, A. Greig, K.D. Collerson, B.S. Kamber, Aquat. Geochem. 12 (2006) 39-72.

[35] L.V. Godfrey, W.M White, J.M. Salters, Geochim. Cosmochim. Acta 60 (1996) 3995-4006.

[36] M.L. Firdaus, T. Minani, K. Norisuye, Y. Sohirin, Nat. Geosci. 4 (2011) 227-230. 